\title{
Yaşantılara Dayalı Öğrenme, Yaratıcı Drama ve Süreçsel Drama İliş̧kileri
}

\author{
H. Ömer ADIGÜZEL" \\ Ankara Üniversitesi
}

\begin{abstract}
Özet
Yaşantılara dayalı ögrenme, eğitimin belirli bir zamanla, planla smtrll ve herhangi bir mekana da bağımlo olmaması gibi temel bir niteliğini gösterir ve bireyde kalıc öğrenmeyi sağlar; bumun için de etkin katılım gerekir: Yaşant, bireyin diğer bireylerle ve çevresiyle etkileşiminin bireyde bmaktı̆̆ı izlenimdir: Yaratıcı drama özellikleri, çok yönlit işleuselliği nedeniyle smif dişndaki amaçlara uygun her türlii ortamlarda özellikle yaşantılara dayah öğrenmeyi gerçekleştirmede etkili bir yöntem ve disiplindir: Yaratıci drama, grup ïyelerinin yaşantllarma dayaltdrr. Diamanm başlangıc noktası ve drama sïrecinin gelişmesi, yaşamnlar somucunda elde edilen birikimlerin işe koşulması ile doğnudan ilgilidir: Dorothy Heathcote çalışmalartyla dramamn eğitimde ve yașanthlara dayalı öğrenmede etkisini göstermiştir: Ontun drama anlayışı katlimcıların yaşanhlarmdan, kullanmak üzere zamanm içinden bir an almmasma, kendi hareket ve kararlarlyla yï̈leşmelerinin sağlammasma ve sonra da doyum sağlayabilecekleri gerçek sonuçlara götïrülmesine dayalıdır. Ona göre programm hedeflerine ulaşabilmek amactyla, çocuklarmn kendi diusïncelerini ve problem çözme becerilerini geliştirebilecekleri içerikler oluşturulmalıdı: Drama çalısmalarinda kathlmctlar role, başka biri olarak değil "onlar o insanlarm yerinde olsalardı ne yaparlard dïsiincesinde rol oynamalidmlar". Bumm yanmda Ezilenlerin Tiyatrosu çalısmasiyla Forum Tiyatro tekniğinin öncïsü olani Agusto Boal'm çalışmalar ile de yaşanthlara dayalı ögrenme arasmda somut ilişki kurulabilir: Fortum Tiyatro tekniği ayn zamanda sïreçsel drama çalısmalarmda bir teknik olarak kullamlm/kullamlabilir:
\end{abstract}

Anahtar sözcükler: Yaşantılara dayalı öğrenme, yaratıcı drama, sïreçsel drama.

\begin{abstract}
Experience is the impression caused by the individual's interaction with other individuals the environments around him. Leaming based on experiences shows that education is not dependent on a certain period of time, a plan or a place and it provides permanent learning in the individual and active participation is required for this. With its characteristics and multiple finctionality creative drama is an effective method and discipline in realising particularly learning based on experiences in any places appropriate for the objectives out of the class. Creative drama is based on the experiences of the group members. The starting point of drama and the improvement of the drama process are directly related to the activation of the experiences gained. Dorothy Heathcote showed the effect of drama in education and learning based on experiences with her studies. Her standpoin in drama is that the participants pick up a moment in time from their experiences to use and it is provided that the participants face their actions and decisions and eventually, they are led into the real results which they can be satisfied with. According to her there should be contents in which the children can develop their own thoughts and problem solving skills in order to reach the objectives of the programme and content. The participants should not act their roles trying to be other people but "they should put themselves imo other people's shoes imagining what they could do if they were those people". Besides, a concrete relation can be built up between learning based on experiences and Agusto Boal, the leader of the rechnique of Forum Theatre with his work entitled The Theatre of the Oppressed. The Fortm theatre technique is/can be used as a rechnique in process drama studies.
\end{abstract}

Keywords: Learning based on experiences, creative drama, process drama. 
Eğitimde Yaratıcı Drama tanımının içerisinde yer alan sözcüklerden bazılarının yaratıcı drama disiplini ve yöntemini açıklamada önemli bir yeri olduğu görülür. En genel yanıyla eğitimde yaratıcı drama; bir grupla her hangi bir konuyu doğaçlama, rol oynama gibi tekniklerden yararlanarak ve grubun, yaşantılarından yararlanarak canlandirmalar yapmaktır.

Bir disiplin olarak drama çalışmalarında veya herhangi bir dersin bir temasının drama yöntemi ve teknikleriyle işlenmesinde (bir yöntem olarak) üzerinde durulması gereken öğeler; bir konunun (temanın), bir grubun, liderin, mekanın ve kullamlacak yöntem-tekniklerin olması, mutlaka bir canlandırmanın yapılması ve bunun da yaşantılardan yola çıkması gerekliliğidir. "Yaşantı, bireyin diğer bireylerle ve çevresiyle etkileşiminin bireyde bıraktığı izlenim"dir. Demirel, yaşantının eğitim açısından kazanılmış ve yaşanılımış yaşantı olarak iki biçimde ele alındığını belirtir. Ona göre kazanılmış yaşantı, bireylerin birbirleriyle etkileşimi sonucunda yer alan etkinliklerin tümünü içermektedir. Yaşanılmış yaşantı ise söz konusu etkileşim içinde yer alan etkinliklerden sadece bireyde kalıcı iz bırakan ve bireyin davranışında değişim oluşturan etkinliklerdir (Ertürk, 1972'den Akt.: Demirel, 1999:6). Yine Demirel'e (1999:9) göre eğitim program1; öğrenene, okulda ve okul dışında planlanmış etkinlikler yoluyla sağlanan öğrenme yaşantıları düzeneğidir.

Yaşantılara dayalı ögrenme bireyde kalıcı öğrenmeyi sağlar, bunun için de etkin katılım gerekir. Sözel ağırlıklı ögretimde \% 10 olan hatırlama ve kalıcılık görselde \% 30, yaşantılara dayalı ögretimde \% 90'a ulaşmaktadır. Eğitim bilimlerindeki, sanatlar eğitimindeki yeni gelişmeler, eğitim sorunlarına bakış açımızı da değiştirmiştir. Cağdaş eğitim yaklaşımlarında öğrenen insanın gözüyle ögrenme sürecine ve yaşantılara öncelik verilmektedir. Öğrenmede öğrenme biçim ve yaklaşımlarının önemi artmıştır. Eğitimde sözel ve bilgi depolanması ağırlıklı ögretimin yerini başta görsel olmak üzere duyulara ve yaşantılara dayalı ögrenme almaktadır.

Yaşantılara dayalı öğrenme, eğitimin belirli bir zamanla, planla sınırlı ve herhangi bir mekana da bağımlı olmaması gibi temel bir niteliğini gösterir. Bilinen bir söylem ile eğitim, çok boyutludur, süreklidir, zaman ve yer açısından sınırsızdır, yaşantılarla kazanılır. Eğitim, yaşam boyu devam eden bir süreçtir. Bu süreç içerisinde önemli bir yere sahip olan öğretim ise öğrenmeyi bir anlamda sağlama, kolaylaştırma işlevine sahiptir. Çünkü "öğrenme, bireyin çevresiyle belli bir düzeydeki etkileşimleri sonucunda meydana gelir" (Senemoğlu, 1997:13) ve belli bilgi, beceri ve anlayışları edinme, davranışlarda her zaman kimi durumlarda yaşantıların oluşturduğu değişmeyi içerir. Öğrenme, yaşantı ürününün kendisidir, öğrenenin yakın ya da uzak çevresi ile kurduğu iletişim, ulaştığı etkileşim sonucunda oluşur. Öğrenmede temel amaç ögrenenin davranışlarında kalıcı izli değişmeler sağlamaktır.

$\mathrm{Bu}$ yönüyle öğrenmenin genel özelliği, davranışta bir değişmenin olması, bu değişmenin sürekli, yaşantı kazanma sonucunda gerçekleşmesidir (Senemoğlu, 1997:95). Öğrenme, bir yönüyle, ögrenenin hayatta kalabilme, kendini geliștirebilme, yaşadığı çevreye uyum sağlama gereksinimidir. Bu gereksinimin duyulması ve yerine getirilmesi durumunda öğrenme gerçekleşebilir. Günümüzde birey, kendisi ve başkalarıyla olan iletişiminde, yaşadığı çevreye uyumunda ve daha yaratıcı olmasında yeni ögrrenme biçimlerine gereksinim duymaktadır.

Ezberciliğin ve öğrenenlere bilgi depolamasının yoğun olduğu çarpık bir ögretim sisteminde yetișen birey, eğitimin geleneksel yapısını koruması ve toplumsal uyguyu aşma çabasının olmaması nedeniyle içinde yaşadığı yenileri yakalayamamakta, eğitimin uygucu sinırları içinde sıkışıp kalmaktadır. Bu sıkışıklık bireyde çözmesi gereken bir ikilem oluşturmaktadır. Birey ya içinde yaşadığı grubun yargılarıyla hemfikir olacak, yani uygucu olacak ya da kendini bir - an önce tanyyacak, kendi görüs ve düşüncelerini savunacak, böylece grubun fikir birliğine karşı bağımsızlığını koruyabilecektir (Adıgüzel, 1993:2, 1999:126). Oysa sistem öğrenciyi (bireyi) merkeze alıp, onu düşünsel etkinliğe yönlendiren, bireye "birey" olma şansı verebilen bir sistem olmalı, yaratıcılığı geliştiren yöntemleri ve yaratıcı bireyi yetiştiren disiplinleri geliștirebilmelidir. 
Yaratıcı drama özellikleri, çok yönlü işlevselliği nedeniyle sınıf dişındaki amaçlara uygun her türlü ortamlarda özellikle yaşantılara dayalı öğrenmeyi gerçekleştirmede etkili bir yöntem ve disiplindir. Çocukların, ergenlerin ve gençlerin gerçek dünya ile kurgusal dünya arasında gidip gelmelerini olanaklı kılan yaratıcı drama, sınıf içi ya da düşünülen pek çok sınıf dışı öğrenme ortamlarında etkili olmaktadır.

Yaratıcı drama, grup üyelerinin yaşantılarına dayalıdır. Drama ortamlarında bir katılımc1 izlediği ya da içinde olduğu canlandırmalarda, kendi ya da başkasının yaşadığı bir sorundan yola çıarak sorunu çözmeye doğru yönelir. Drama yaşantılarında bir katılımcı herhangi bir konuyu, tüm duyularını harekete geçirerek yani yaşayarak öğrenir. Bu öğrenme mutlaka bir grup içi etkileşimin bir sonucu olmak durumundadır. Öğrenme açısından bakıldığında yaratıcı drama, öğrenenin kendi olduğu, konuyu belirlemede ve irdelemede etkin olduğu ve sonuçta yine kendi yaşamında kalıcı izli davranışa dönüşen süreçleri bireye yaşatır.

Bir drama yaşantısında birey diğer katılımcularla birlikte drama liderinin yönlendirmesinde tüm yaşantıların içindedir, katılımcı gerçek yaşamda devam eden rolüne, kimliğine kendisinin ve grubun yaşantılarından yola çıkarak bir anlamda ayna tutar, çeşitli canlandırmalarla yaşamda olas1 yeni yollara, "ana ve ara sokaklara gider". $\mathrm{Bir}$ arayış, merak, bulma isteği söz konusudur. $\mathrm{Bu}$ istek içerisinde yer yer yarışma ögesinin de olduğu gerilimler yaşanır ki bu da tüm drama katılımcılarına bir haz yaşatır. $\mathrm{Bu}$ haz oyunda olan eğlenceden, özgürce yaratmalardan, öyleymiş gibi yapma özelliklerinden kaynaklanır (Ad1güzel, 2002; 2006).

"Dramanın doğasında bir etkileşim vardır ve bu etkileşim insanın insanla karşılaşmasında ortaya çıan bir olgudur. Alman oyun ve tiyatro pedagogu Nickel için etkileşim, bir insanın bir diğerine göre kendini uydurması, "karşılıklı koşullandırmalı davranışlarda, birinin etkinliğini diğerlerininkinin izlemesi ama ikincisinin eyleminin aynı zamanda gene onun etkinliğinden devinim kazanmasıdır. Böylesi bir etkileşimin oluşabilmesi için, bu durumu paylaşanların, bir eylemin anlamı hakkında aynı düşünüye sahip olmaları, temelde anlaşmaları gereklidir" (...) İnsanın insanla arada başka bir malzeme olmaksızın etki tepki alışverişine girebildiğgi" (San, 1990:575) öğrenme ortamları söz konudur ki bu öğrenme ortamlarının en somutu, oyun ve yaratıcı drama ortamlarıdır.

Yaratıcı drama alanında İngiltere'de önemli bir çığır açmış olan Dorothy Heathcote, dramanın eğitimde ve yaşantılara dayalı ögrrenmede etkisini göstermiştir. Başlangıçta eleştiriler almasına rağmen Heathcote'un drama çalışmalarında çocuk, ergen ya da yetişkinlerin hissettiği, yaşadığı duygular, heyecanlar, gerçek duygulardır ve drama lideri de bu tür bir görevi üstlenmelidir. Heath- cote; "Eğer dünyayı çocuklar için daha basit ve anlaşılabilir yapacak bir yol varsa, neden kullanılmasın?" görüşündedir. Ona göre bir konunun sadece herhangi bir yol ile (ya da tek bir yol ile) ögrretilmemesi gerçeklerin ötesinde, herhangi özel bir konunun daha evrensel olan boyutlarının görülmesinin sağlanması çalışmalarının yapılması gere- kir (Sağlam,1997:25).

Heathcote drama işleyişinde eğitselliği vurgulamaktadır ve dramanın öğrenme için etkin bir yöntem olduğuna inanmakta, dramayı 'yaşamın pratiği' olarak açıklamaktadır (...) Onun drama anlayışı katılımcıların yaşantılarından, kullanmak üzere zamanın içinden bir an alınmasına, kendi hareket ve kararlarıyla yüzleşmelerinin sağlanmasına ve sonra da doyum sağlayabilecekleri gerçek sonuçlara götürülmesine dayalıdır (...) Ona göre programın hedeflerine ulaşabilmek amacıyla, çocukların kendi düşüncelerini ve problem çözme becerilerini geliştirebilecekleri içerikler oluşturulmalıdır. Drama çalışıalarında katılımcılar role, başka biri olarak değil 'onlar o insanların yerinde olsalardı ne yaparlardı?' düşüncesinde rol oynamalıdırlar (Pollisini, 1994, Akt: Akar, 2000: 41-42). Gerçek yaşantılar oluşturma anlayışı, 90'lı yıllarda İngiltere'de ve Türkiye'de daha yaygın kullanılmasıyla başlayan süreçsel drama ile (process drama) daha belirginlik kazanmıştır. Bu yaklaşım, birçok olayın gerçek yaşamda (katılımcıların) başlarına gelmesini beklemek yerine, çocukların (katılımcıların), kurgusal ortamlarda gerçek yaşantılar 
geçirerek, gerçek yaşamda daha deneyimli olmalarını sağlayarak, onlara deneyim zenginliği kazanmaları için fursat oluşturma (Akar, 2000:42) esasına dayanır. Heathcote için yaratıcı drama, bir araç değil, çocukların kendilerini rahatça ifade edebilecekleri, sorunları çözebilecekleri, kendi yaşam deneyimlerine katabilecekleri bir amaç olmalıdır. Heathcote'un drama anlayışı katılımcıların yaşantılarına odaklanır. Onların yaşantılarından bir "an" alınır, onların kendi hareket ve kararlarıyla bir sonuca gitmeleri sağlanır. Sonuca ulaşma durumunda da katılımcıların bundan zevk alacakları gerçek sonuçlara gidebilmeleri beklenir. Böylece birçok olayın gerçek hayatta başlarına gelmesini beklemek yerine, katılımcıların kurgusal ortamlarda gerçek yaşantılar geçirerek, gerçek yaşamda daha deneyimli olmalarını sağlayarak, onlara deneyim zenginliği kazanmaları için firsat oluşturur. Bu bağlamda yaratıcı drama katılımcılar için dünyayı ve olayları daha basit ve anlaşılır kılabilir. Drama süreçleri gerçekmiş gibi yaşanır, çünkü drama gerçek hayatta bulduğumuz kuralların aynısını kullanır. Drama, "yaşamı oynama ve uygulama" aracıdır. Bir katılımcı için başka yerlerde ve zamanlarda, başka insanların başına gelen olaylara bakmayı veya bir olay sonucunda kişinin kendi deneyimlerini incelemesini olanaklı kılar. Bu durum yaşantı odaklı çalışmaları geniş ölçüde içeren süreçsel drama ile de örtüşür.

Süreçsel dramada katılımcı bir durumun, çatışmanın içine girer, kurgusal gerçeklikte bu çatışmayı yaşar, grupla ve grup içi iletişimle irdelemeye başlar, dener, sorgular, yeniden analiz eder ve gerçekle kurgusal gerçeklik arasında özellikle drama tekniklerinin de yol göstermesiyle süreci yaşar ve bu sürecin devamını da belirler. $\mathrm{Bu}$ nedenle bu tür çalışmalarda verilen bilginin tartışılmadan aynen kabul edilmesi, davranışa dönüştürülmesi gibi bir olgu söz konusu değildir. Heathcote, dramayı güçlü bir ögretim aracı olarak görmüştür.

Pamela Bowell ve Birian S. Heap'a göre süreçsel drama, dışardan seyircileri yok sayıp içerdeki seyircileri önemli gören bir yaklaşıma sahiptir. Diğer tiyatro biçimlerinin anlamını aktörler, oyun yazarları, yönetmenler, donatım- cılar oluştururken, süreçsel drama gruplarında katılımcılar lider/öğretmenle birlikte dramanın anlamını kendileri, kendileri için oluşturur ve sorgularlar. Temelde bu tür çalıșmalarda gruplar doğrudan doğaçlama yaparak, tavırlardan, davranışlardan, görünüşlerden ve düşüncelerden etkilenirler. Dorothy Heathcote'a göre süreçsel dramada önemli olan şimdiki zamanı keşfederek çalışmak ve hayatın hızına uyarak yaşamaktır. Süreçsel dramada katılımcılar kendilerine verilen bir öyküyü, metni canlandırma yerine, etkileşim, olay ve etki-tepki biçiminde birleştirip öyküleştirerek ve gerilim katarak kendi öykülerini oluşturabilirler. $\mathrm{Bu}$ çalışmalarda dramatik anların çeşitli materyallerle gelişmesi, katılımcıların çeşitli roller alarak gerekli araștırmaları yapması ve konunun geliştirilmesi süreç açısından önemlidir. Öğretmen/liderin görevi katılımcılarla iletişim kurmanın yollarını bulmaktır. Bu yolları bulmak için onların yanıtlarını düşüncelerini göz önünde bulundurarak onlara ulaşmalıdır. Bu nedenle sorunların çözümünde uygun stratejileri bulmak ve bunları materyallerle doğru ilişkilendirmek, doğru bağlantılar kurmak durumundadır (Bowell ve Heap, 2001:7).

Bowell ve Heap, Dorothy Heathcote'un çalışmalarından yola çıkarak süreçsel dramanın genel planlamasında altı temel ilke üzerinde dururlar. Onlara göre bu ilkeler hangi yaş grubuna uygulanırsa uygulansın geçerlidir ve çalışma öncesinde dikkat edilmesi gereken ilkelerdir. Bu ilkelerin tamamı bir yaratıcı drama sürecinde katılımcıların yaşantılarına odaklanır ve süreç, katılımcıların yaşantılarını işe koşmaları ile gelişir. Bu ilkeler 1. Tema/Öğrenme Alanı: Drama bir "şey" hakkında olmalıdır. Bu içerik bir ders konusu olabileceği gibi eğitimsel amaçlı seçilen her "şey" olabilir. Bu aynı zamanda seçilecek odak noktasının kendisidir. 2. İçerik: Öğrenme alanlarını ya da temayı seçerken odaklanmanın nerede olacağına karar vermek gerekir. Bunun için dramatik içeriği geliştirmek gereklidir. Bu içerik kurgusal şartları sağlamalıdır. $\mathrm{Bu}$ da konunun ortaya çıkartılmasını sağlar. 3. Roller: Dramada en önemli etkinlik rol almaktır. Öğrencilerin ve ögretmenin rolü bu bağlamda ne olacaktır, bunun daha önceden belirlenmesi gerek- 
lidir. 4. Çerçeve/Taslak: Drama çalışmalarında gerilim (dramatik) anları yaratmak için rollerin nasıl yönleri olmalı ve rolleri ne derece belirlenmelidir? 5. İşaret/ Araç-gereç: Olayların önemini belirlemek için ne gibi eserlere, kişisel unsurlara, seslere, imgelere gereksinim olacak? Önemli olan tüm katılımcıların dikkatini tam sağlayacak temel anahtarları, yolları bulmaktır. Bu yollar sanatsal gerçekler, kişisel nesneler, dokümanlar, imajlar, çeşitli objeler olabilir. 6. Stratejiler: Hangi çalışma yöntem ve tekniklerinin kullanılacağı burada önemlidir. Hangi amaçla, nasıl bir ilişki kurarak sorunu çözeceğim. Drama sürecini oluşturmanın, başlatmanın, ileriye götürmenin, içinde olanları yansıtmanın ve sonuçlarını almanın birçok yolu vardır. Bilinçli bir strateji seçimi katılımcılara sanat biçimini ögrenmede, dramanın içeriğini anlamada ve onu yansıtmada yarar sağlayacaktır (Bowell ve Heap, 2001;1012).

Norman'a göre (1981:50'dan Akt.: San, 1990:579) drama etkinliği drama yaşantısının somut olarak duyumsanmasıyla kişinin evrensel, toplumsal, etik ve soyut kavramları anlamlandırmasıdır. Bu anlamlandırmada gerçek dünya ile kurgusal dünya arasında gidip gelmeler, sorunu irdeleme ve çözme durumları söz konusudur.

Bunun yanında "Ezilenlerin Tiyatrosu" çalışmasıyla "Forum Tiyatro" tekniğinin öncüsü olan Agusto Boal'in görüşleri ile yaşantılara dayalı öğrenme arasında somut ilişki kurulabilir. "Forum Tiyatro, yaratıcı drama ortamında katılımciyı (aynı zamanda işlevi gereği tiyatroda izleyiciyi) kendi sorunlarına bakmaksızın ve sorunun çözümüne yönelik geçerli çözümler üretmesine yönlendirir. Bu sorunlara ve çözümlere 'müdahale' hakkı için forum tiyatro tekniği katılımcıyı harekete geçirir, sürece katkı getirme, doğrusunu gösterme ve uygulama olanağı verir. $\mathrm{Bu}$ bir anlamda katılımciya "bunu yapabilirsin" demektir ve "gel sürece katıl, kendi yaşantılarından yola çık ve hem kendin hem de diğer katılımcılar için sorunu çöz" anlamı taşımaktadır.

"Boal için tiyatro, gerçek yaşamın provasıdır. Seyirci baş kahraman olarak seyirci durumundan seyirci-oyuncuya dönüşerek dramatik eylemi değiştirir, çözümleri dener, kendini gerçek yaşam içinde karşılaşabileceği eylemler için eğitir (...) Boal, tüm insanların hem seyrettiğini yani seyirci olduklarm, hem de eylemde bulundukların yani seyirci oyuncu olduklarını öne sürer ve poetikasının hareket noktasını da bu görüş oluşturur. Bu görüşün aynı zamanda seyircinin doğasında var olan oyunu, oyunun gidişatını ve senaryonun sonucunu kontrol altına alma isteğinin bir uzantısı olduğunu öne sürer (Kuyumcu ve Iogna, 2001:4; Boal, 1996, 2003a, 2003b)". Forum Tiyatro tekniğinin temelinde de sosyal etkinlikler yatar ve bu nedenle sürekli değişme, değiştirme olanaklarına sahiptir. Katılımcı, (ya da seyirci) bu değişimi yaratacak, uygulayacak önemli bir güç, etkendir. Bir insanın yaşamındaki öğrenmeler yaşantılara dayal 1 olarak oluşur. Bu oluşumda tüm duyularını kullanan birey, öğrenmelerini yaşamın geneline yayar ve kalıcı izli davranışları oluşturur. Yaparak, yaşayarak, hissederek, duyular yoluyla öğrenme ona tüm yaşamı boyunca benzer yaşantılarda karşılaştı̆̆ı sorunları çözmede kolaylıklar sağlayacaktır.

Öğrenmede geliştirilmesi gereken davranışın içselleştirilmesi ile yaratıcı drama disiplini ve yönteminin temel işlevleri arasında doğrudan bir ilişki söz konudur ve özellikle drama tekniklerinin daha etkin kullanıldığı öğrenme ortamlarında yapılacak çalışmalar, sonuca ulaşmada etkin olacaktır. Yaratıcı drama ortamları katılımcısını etkin olarak sürece katılıma yöneltir. Sözgelimi Sosyal Bilgiler derslerinin bir temasının forum tiyatro tekniği ile ya da süreçsel drama ile işlenmesi, yaşantılara dayalı öğrenmeyi daha somut hale getirebilir.

Sonuç olarak yaratıcı drama; öğrenme açısından pek çok diğer öğrenmelerde olduğu gibi yaşantılara dalalı öğrenme ile iç içedir. Başka bir yönüyle yaratıcı drama, özellikle süreçsel drama ve forum tiyatro tekniklerinin etkin kullanım ile yaşantılara dayalı ögrenmenin kendisi olabilir ve bu tür öğrenme etkinliklerinde de kullanılabilir. 


\section{Kaynaklar}

Adıgïzel, H. Ö. (1993). Oyun ve yaratıc drama iliskisi. Yayınlanmamıs yüksek lisans tezi. Ankara: Ankara Üniversitesi

Adıgïzel, H. Ö. (1999). Türk eğitim sisteminde yaratıcı drama ögretmeni yetiştirme sorunsalı. 8.Ulusal Eğitim Bilimleri Kongresi, KATÜ, Trabzon.

Adıgüzel, H. Ö. (2002). Eğitim bilimlerinde ve sanat eğitiminde yöntem, disiplin ve sanatsal boyutlaryyla yaratıc drama. 11. Eğitim Bilimleri Kongresi. Yakın Doğu Üniversitesi: KKTC, 23-26 Ekim.

Adıgüzel, H. Ö. (2006). Eğitimde Yaratıc Drama (baskıda). Ankara: Natürel Yayınları.

Akar, R. (2000). Temel eğitimin ikinci aşamasmda drama yöntemi ile tiirkce ögretimi: Dorothy Heathcote'un 'Uzman Rolï Yaklaşım'. Yayınlanmamış doktora tezi. Adana: Çukurova Üniversitesi.

Boal, A. (1996). Ezilenlerin Tiyatrosu (Çev:Semih Çelenk) İzmir: Etki Yayınlan,.

Boal, A. (2003a). Ezilenlerin Tiyatrosu (Cev.: Necdet Hasgiil), İstanbut: Boğaziçi Üniversitesi Yayınları,
Boal, A. (2003b). Oyuncular ve Oyuncu Olmayanlar Için Oyunlar (Çev.: B. Ataman, Ö.Öztürk, K.Ruzvanoğlu).

Bowell P. ve Heap, S. B. (2001). Planning Process Drama, Londra: David Fulton Publishers,.

Demirel, Ö. (1999). Planlamadan Değerlendirmeye Ögretme Sanatı, Ankara: Pegem A Yayınları

Kuyumcu, N., Ioagna L. (2001). Haydi Çocuklar Sahneye, Ankara: Kültür Bakanlığı Yayınları

Pollisini, J.K. (1994). The Crearive Drama Book; Three Aproaches, New Orleans: Ancli Orage Pers.

Sağlam, T. (1997). Eğitimde drama ve türk çocuklarmm ritïel nitelikli oyunlarmin eğitinde dramada kullanmm. Yayımlanınamıs doktora tezi, Ankara: Ankara Üniversitesi.

San, I. (1990). Eğitimde yaratıcı drama. Ankara Üniversitesi Eğitim Bilimleri Fakuiltesi Dergisi. 23, 2, 573-582.

Senemoğlu, N. (1997) Gelişim Öğrenme ve Ögretim Kuramdan Uygulamaya. Ankara: Ertem Matbaacılık. 


\title{
Summary \\ The Relationship Between the Learning Based on Experiences, Creative Drama and Process Drama
}

\author{
H. Ömer ADIGÜZEL * \\ Ankara University
}

Experience comes from impression education programme caused by the individual's interaction with other individuals and groups and the mechanism of learning experiences of the learner caused by planned events in or out of the school.

Learning based on experiences provides permanent learning in the individual active participation is required for this kinclof learning. Permanence and remembering is $10 \%$ in the verbal education whereas it might increase up to $30 \%$ in visual learning and $90 \%$ in learning based on experiences. New developments in educational sciences and arts education have changed our points of view of education problems. The priority today in the contemporary education approaches is to focus on learning process and life with the eyes of the person learning. Teaching of knowledge storing was taken over by visual teaching and particularly learning based on experiences. Learning based on experiences shows that education is not dependent on a certain period of time, a plan or a place. With its characteristics and multiple functionality creative drama is an effective method and discipline in realising particularly learning based on experiences in any places appropriate for the objectives out of the class. Creative drama is based on the experiences of the group members. In drama environments, a participant who watches or takes part in animations tends to solve a dramatic moment or a conflict with his or someone else's own experience. A participant learns any content by activating his all senses in the drama environment; he leams by living. This learning should definitely be a result of an interaction within the group.

From the learning aspect, creative drama experiences form the situations where the leamer is himself and active determining and studying the content and eventually gains the permanent behaviour.

Dorothy Heathcote showed the effect of drama in education and learning based on experiences with her studies. Her standpoint in drama is that the participants pick up a moment in time from their experiences to use and it is provided that the participants face their actions and decisions and eventually, they are led into the real results which they can be satisfied with. According to her, there should be contents in which the children can develop their own thoughts and problem solving skills in order to reach the objectives of the programme and content. The participants should not act their roles trying to be other people but they should put themselves into other people's shoes imagining what they could do if they were those people. Besides, a concrete relation can be built up between learning based on experiences and Agusto Boal, the leader of the technique of Forum Theatre with his work entitled The Theatre of the 
Oppressed (and this technique is/can be used as a technique in process drama).

Forum theatre leads the participant (also a member of the audience in theatre due to his function) to create valid solutions, regardless of his own problems in creative drama environment. The Forum theatre technique activates the participant by giving him the right to 'interfere' with these problems and solutions and provides him to contribute to the process and to show and practice what he thinks right. This means saying "you can do this" to the participant somehow and it means "come join the process, start from your own expe- riences and solve the problem for your and the other participants' sake". Theatre, for Boal, is the rehearsal of real life. The spectator turns into the spect-actor where he becomes the protagonist and changes the course of the dramatic action, tries out the solutions, and trains himself for the actions he might face in real life. Boal claims that all people watch, which means they are all spectators and that they are all in some action, which means they are spect-actors and this forms Boal's standpoint. He also claims that this point of view is an extension of the spectator's desire to control the play, which is in his nature, its course and the result of the scenario. 